Article

\title{
Strategies for the mobilization and deployment of local low- value, heterogeneous biomass resources for a Circular Bieconomy
}

\author{
Fabian Schipfer ${ }^{*}$, Alexandra Pfeiffer ${ }^{2}$ and Ric Hoefnagels ${ }^{3}$ \\ 1 Technische Universität Wien; schipfer@eeg.tuwien.ac.at \\ 2 Deutsches Biomassforschunszentrum; alexandra.pfeiffer@dbfz.de \\ 3 Utrecht Universiteit; r.hoefnagels@uu.nl \\ * Correspondence: schipfer@eeg.tuwien.ac.at
}

\begin{abstract}
The European Bioeconomy Strategy aims to strengthen and boost biobased sectors, unlocking investments and markets while rapidly deploying local bioeconomies across Europe and improving compliance with environmental and social sustainability goals. Current biomass provision structures and infrastructure might not be able to tap the sustainable potential of forestry-, agricultural residues and biogenic waste envisaged forming the biogenic feedstock base of the Circular Bioeconomy of tomorrow. Therefore, for the present paper, we assess mobilization strategies, their current status, opportunities, and barriers for local low value and heterogenous biomass resources. Based on discussions with bioenergy supply chain experts, we cluster mobilization measures into three assessment levels; the legislative framework, market structures and technological innovation. Scientific literature research on the respective keywords is performed, the European policy landscape mapped, and the results are enriched with anecdotal evidence, especially for recent and running projects and market developments that lack in published track records. We can identify research needs on all three assessment levels. Still, technological development and legislative frameworks are providing support for heterogeneous biomass mobilization. Market creation, however, represents a bottleneck. We provide novel perspectives, how physical- and virtual bio-hubs and crediting stake- and shareholder variety could create added-value based on sustainable primary economic activities and their cascading activities.
\end{abstract}

Keywords: Bioeconomy strategy, regional development, residues, policy, market, technology, commoditization 


\section{Nomenclature}

BBI JU Biobased Industries Joint Undertaking

BECCS Bioenergy Carbon Capture \& Sequestration

CAP Common Agriculture Policy

CBE JU Circular Bioeconomy Joint Undertaking

CE Circular Economy

CHP Combined heat and power

$\mathrm{CO} 2$ Carbon dioxide

EESCEuropean Economic and Social Committee

EFA Ecological Focus Areas

eRA Electronic Reverse Auctioning

EU European Union

GHG Greenhouse Gas

GIS Geographic Information System

ha Hectare

IEA International Energy Agency

KPI Key performance indicator

LOHC Liquid organic hydrogen carriers

M.S. Member States

MLG Multi-level governance

MwelMega watt electric

NUTS Nomenclature of Territorial Units for Statistics

OECD Organisation for Economic Co-operation and Development

P.V. Photo voltaic

R\&D\&D Research, development and deployment

RED Renewable energy directive

SME Small and medium enterprises

SRC Short-rotation coppice

TCP Technology Collaboration Programme

U.K. United Kingdom

U.S. United States 


\section{Introduction}

The European Bioeconomy Strategy [1] aims to strengthen and boost biobased sectors, unlocking investments and markets while rapidly deploying local bioeconomies across Europe and improving the understanding of ecological boundaries. By definition, this includes "all primary production sectors that use and produce biological resources (agriculture, forestry, fisheries and aquaculture); and all economic and industrial sectors that use biological resources and processes to produce food, feed, bio-based products, energy and services. To be successful, the European bioeconomy needs to have sustainability and circularity at its heart."

On the other hand, and since the 1970's, industrial ecology and industrial metabolism discussions coin the term Circular Economy (C.E.). The C.E. has been used as a guideline in policy-making, especially in China and Europe. However, policies mainly focus on the end-of-use step of the life-cycle (e.g. waste treatment). The other steps, production/product design, use phase/consumption and resource circulation, are not yet addressed in most sectors so far [2]. While the C.E. is mainly attributed to electronic waste and recently also plastics[3], the Annex of the draft proposal for a European Partnership for a Circular bio-based Europe [4] argues why a Bioeconomy is inherently a Circular Economy; biobased sectors have $\mathrm{CO}_{2}$-avoidance and retention, reduction, recycling and reuse of wastes and residues as its goals, all traits which have been primarily credited to the Circular Economy.

The current and commercial provision of biobased energy services is mainly based on wood chips, wood pellets or $1^{\text {st }}$ generation biofuel plantations [5]. The underlying resources are mobilized primarily for material services (e.g., construction wood, pulp and paper) [6], while $1^{\text {st }}$ generation biofuel resource provision use similar production techniques and supply chains as agricultural production. As a result and in their review on bioenergy supply and demand scenarios and projections [7] stress a potential mismatch due to limited modelling and analysis of crucial conversion processes between fresh biomass and end-user services. A plethora of underutilized, non-commodity biomass resources can be categorized in energy crops-, agricultural residues and waste [8-11]. These resources could become the feedstock basis for the circular bioeconomy services of tomorrow. However, they are diverse in, e.g., physical properties (energy density, moisture content, ash content but also contamination such as sand/plastic), origin (landscape management, residential garden/kitchen waste) and legal status (waste v.s. resource/material). In contrast to current provision structures, this diversity will demand additional mobilization efforts.

For the present paper, we are assessing strategies for mobilizing and deployment of local low value and heterogenous biomass resources for a circular bioeconomy that could at the same time provide support to structurally weak regions. We follow up with the research question on the current status, opportunities and barriers of biomass mobilization measures. The research focuses on the European Union concerning policies but is also inspired by developments in the rest of the world.

\section{Materials and methods}

This work is based on an extensive discussion on biomass mobilization strategies between International Energy Agency (IEA) Bioenergy Technology Collaboration Programme (TCP) Task 40 researchers. The expertise of the authors and discussion participants undoubtedly defines the scope of the presented findings. The Task40 initially focused on international bioenergy trade. The established supply-chain knowledge, however, proved to be applicable to strategic questions about biomaterials as well (see, e.g., [12]). The international consortium specializes by now on the "deployment of biobased value chains" in support of a broader, circular bieconomy. Following the zeitgeist, as, 
e.g., discussed for energy system models reviews in [13], increasing spatial, temporal and sectoral resolution coins the current project objectives, which is dedicating a Task40 task force on Regional Transitions studies. For the sake of this paper, we understand 'region' as an area that could have its characteristics or even administration. We refrain from setting a precise definition, but as a rule of thumb, 'regions' and 'regional' and 'lo$\mathrm{cal}^{\prime}$ could span from municipalities, the lowest local administrative unit to groups of districts, or the NUTS 3 level.

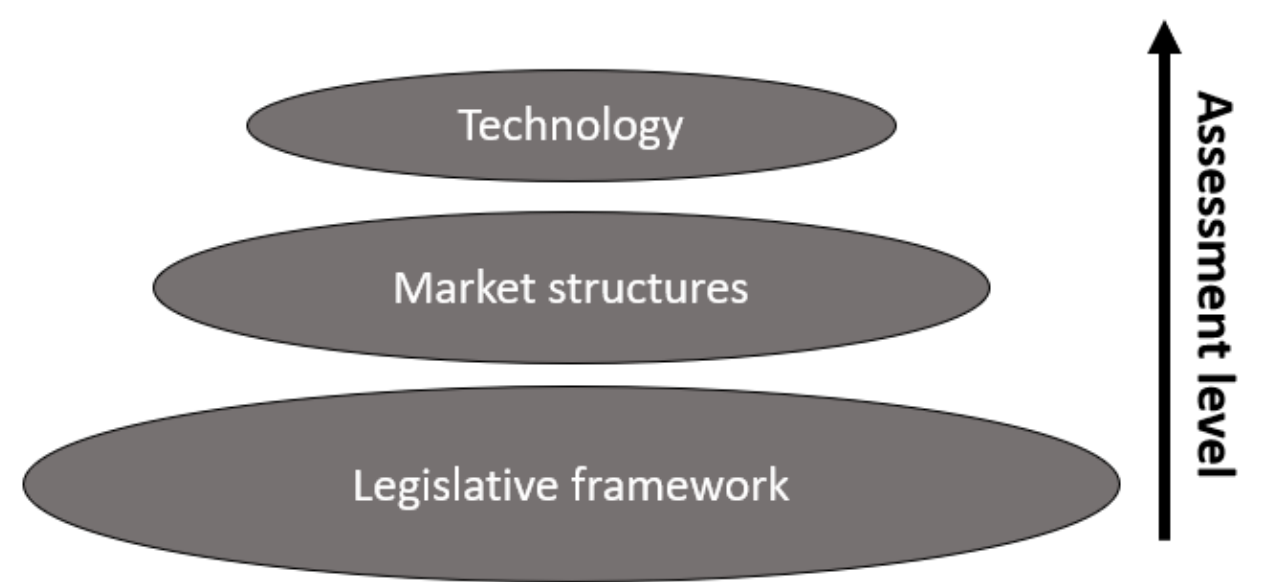

Figure 1: Biomass mobilization strategy categories. The arrow points in the direction of increasing

During the discussions within the task force and based on previous works on mobilization strategies for bioenergy of lower spatial and sectoral resolution (e.g., [5]), we collect information on respective current developments, barriers and opportunities. The discussion is further complemented with scientific literature research on the identified topics and a collection of unpublished research- and development projects to provide the reader with ideas for follow-up scientific-, market- or patent research.

The here presented collection does not claim completeness or indicates any ranking of importance, effectiveness or similar. Still, to facilitate the analysis and discussion beyond the project, we cluster the topics into three categories, legislative framework, market structures and technological innovation (see Figure 1).

This paper's results and discussion (Section 3) are structured following the outlined categories, starting with the lowest assessment level, highlighting top-down the current developments, opportunities, and barriers in the European legislative framework before zooming into biomass markets for energy and material use. The results section is completed with the highest assessment level on bottom-up technological innovation mobilization strategies. The conclusions section (Section 4) provides recommendations and limitations of the present study. 


\section{Results and discussion}

\subsection{Legislative framework for biomass mobilization}

For the basic assessment level of biomass mobilization strategies, we focus on the European Union and its common legislative framework for the 26 Member States (M.S.). We first and foremost are interested in high-level documents labelled "strategy", "blueprint", "roadmap", or "action plan". Even though these terms lack clear definitions and unambiguity, they are often used sequentially (1) with a strategy outlining a general perspective for development, while (2) blueprints and roadmaps are frequently used to illustrate one or several development paths and timelines. (3) Action plans should include concrete steps or action points and preferably quantifiable goals. On an E.U. level, respective documents facilitate the non-juridical discussion of overall trends, even though outlined targets and measures are of non-binding characters eventually to be implemented in regulations and directives. E.U. regulations are binding in their entirety in all Member States/M.S., while directives are to be "transposed" into national laws of the M.S. In contrast, decisions (addressing particular States or organisations) and ordinances on a national, regional or sub-regional level are out of the scope of the present paper.

\subsubsection{EU policy environment affecting regional biomass mobilisation}

The European Green Deal lays down the strategy for a broad set of E.U. policies currently formulated and enacted between 2019 and 2024, building upon the existing policy framework [14]. To achieve climate neutrality by 2050, the Climate Target Plan proposes to cut Greenhouse Gas (GHG)-emissions by 55\% in 2030 through a combination of legislation on the Emission Trading System (ETS), Effort Sharing, and Land Use (E.C., 2020a). The current proposal on revising the Renewable Energy Directive (RED) includes the amendment of renewable energy targets to $40 \%$ by 2030 , quantitative sector-specific renewable energy goals for buildings, transport, industry and district heating and the tightening of sustainability criteria for biomass [16]. Biodiversity protection in forests, GHG saving criteria for existing bioenergy installations (as small as $5 \mathrm{MWel}$ ), phase-out of electricity-only production from biomass (with exceptions), and enforced cascading principles are proposed by the commission.

Coherence with already existing and to-be-revised documents has to be ensured. The primary strategy (or action plan) on the European level for biomass mobilization can be seen in the updated E.U. bioeconomy strategy [17]. This document complements similar objectives to the 2012 bioeconomy strategy with main action areas, including deploying local bioeconomies rapidly across Europe. A Strategic Deployment Agenda (SDA) for sustainable food and farming systems, forestry and bio-based production in a circular bioeconomy was envisaged to be finalized by 2021. This "roadmap" will optimize synergies between the Common Agricultural Policy (CAP), maritime and fisheries policies, the Agricultural Fund for Rural Development (EAFRD), other European Structural and Investment Funds (ESIF) and mobilize the agricultural European Innovation Partnership (EIPAGRI).

Furthermore, local bioeconomy development is supported for coastal (e.g. Blue Bioeconomy grants), urban (Urban Circular Bieoconomy Strategy funding) and rural areas (in national CAP strategic plans). The strategy also aims at piloting carbon farming initiatives to "make carbon sequestration and emission reduction a profitable farming/forestry activity". Finally, E.U. Bioeconomy policy support facilities (via the BIOEAST initiative) and a European Bioeconomy Forum for M.S. is initiated. Furthermore and under the Green Deal, the Just Transition Mechanism (JTM), including the Just Transition Fund (JTF), the InvestEU "Just Transition" scheme, and the European Investment Bank (EIB) public sector loan facility will provide support to "reduce regional disparities and to address 
structural changes in the E.U." related to the transition towards climate neutrality. Also, the public-private partnership for Circular Bioeconomy R\&D\&D, (now CBE JU, former bio-based industries joint undertaking - BBI JU) with potential impacts on biomass mobilization has to be mentioned as an essential tool to foster innovation in regions to mobilize biomass for a circular bioeconomy.

Focusing on regional development, the E.U. Long-term Vision for Rural Areas aims at strengthening the provision of "food, homes, jobs, and essential ecosystems services". Proposed measures include a rural revitalization platform, R\&I for rural communities, boosting digital connectivity and competencies, establishing carbon-sink focus areas and fostering rural entrepreneurship [18]. The Farm to Fork Strategy addresses sustainability throughout the life-cycle of our nutrient services, including production, processing/distribution, consumption and food loss and waste prevention [19]. The Forest Strategy for 2030 promotes a sustainable forest bioeconomy, including the use of wood-based resources but also ecotourism while "ensuring forest restoration and reinforced sustainable forest management for climate adaptation and forest resilience" [20]. The Biodiversity Strategy for 2030 aims at the same time to establish and extend an "EU-wide network of protected areas on land and at sea" and announce "binding nature restoration targets" [21].

More specifically, and based on the current CAP (2014-2020), farmers have to set aside a mandatory share of $5 \%$ of farmland for Ecological Focus Areas (EFAs), including "grasslands, hedges, buffer strips or nitrogen-fixing crops" [22]. Short rotation plantations (SRP), including short rotation coppice (SRC) and single-stemmed trees (SRF), count towards EFAs. However, implementation of these greening measures is still limited to about 50.000 ha in Europe, with considerable shares in Sweden due to an unrelated willow plantation trend between 1986-1996 and some measures such as establishment grants in the UK, Ireland and Germany [23].

\subsubsection{Regional strategies focusing on regional biomass mobilization}

Historically, the E.U. Biomass Action Plan from 2005 aimed at setting out "measures to increase the development of biomass energy from wood, wastes and agricultural crops by creating market-based incentives" [24] To promote regional structures, the E.U. Biomass Action Plan was followed up by several regional biomass action plans, bioenergy action plans and regional development plans. These plans are often developed for specific regions, countries, and sometimes inter-regional partnerships by transdisciplinary project consortia, including research and regional energy agencies, biomass associations, and regional stakeholders. Renown projects, their funding source and runtimes are listed in Table $\mathbf{1 .}$ 
Table 1. Projects aiming at creating and implementing regional biomass action plans with multiregional and international scopes. Source: own elaboration

\begin{tabular}{ccc}
\hline Funding agency & Project name & Project years \\
\hline IEE $^{1}$ & REGBIE+ & $2007-2009$ \\
EFRD $^{2}$ & 4Biomass.eu & $2009-2011$ \\
IEE $^{1}$ & Bioregions.eu & $2010-2013$ \\
Interreg $^{3}$ & Bio-En-Area & $2011-2015$ \\
IEE $^{1}$ & Biomass Policies & $2013-2016$ \\
FP7 $^{4}$ & S2Biom & $2013-2016$ \\
IEE $^{1}$ & Basis & $2013-2016$ \\
Horizon2020 & BioVill & $2016-2019$ \\
Interreg & Bio4Eco & $2016-2020$ \\
Nordic Council of Ministries & Nordic Bioeconomy Prgrm & $2018-2022$ \\
Horizon2020 & BioEastsUp (initiative) & $2019-2022$ \\
\hline
\end{tabular}

${ }^{1}$ Intelligent Energy Europe, ${ }^{2}$ European Funds for Regional Development, ${ }^{3}$ Innovation \& Environment Regions of Europe Sharing Solutions, ${ }^{4} 7$ th Framework Programme for Research of the European Commission, ${ }^{5}$ Horizon2020 Funding Programme of the European Commission

The selection of the projects listed in Table 1 is based on their multi-regional and international scope. Project consortia consist of partners from 6-13 Member States, some also including neighbouring countries. Following up on the E.U. Biomass Action plan projects until 2013 mainly focused on creating action plans and action plan templates and improving regional policies for bioenergy uptake and market creation. Older, potentially fitting projects such as 'Make-it-BE', 'BioMob', 'BioCLUS' and 'RokFOR' are mentioned in the review on regional biomass planning by [25] but information on these projects is insufficient for further analysis. Since 2013, sustainable and efficient use of biomass and the interaction between biomaterial, food and feed and bioenergy based on supply chain approaches is in the foreground. For this purpose, especially the 'Biomass Policies' and the 'S2Biom' projects mapped sustainable supply potentials. They are published as openly accessible and "updated harmonized datasets at a local, regional, national and pan-European level for EU28, Western Balkans, Moldova, Turkey and Ukraine". [26] More recent projects focus on establishing "knowledge-bio hubs" and "bio villages", exchanging information and know-how between regions. The Nordic Council of Ministries representing Denmark, Finland, Iceland, Norway, Sweden, the Faroe Islands, Greenland and Åland furthermore established the 'Nordic Bioeconomy Programme' to collaboratively improve the use of biogenic residues and to remain in a leading position with regard to regional bioeconomy development.

European regions concerned about structural losses in the primary economic sectors through the fossil fuel phase-out also show interest in strengthening local and regional bioeconomies. These regions include mainly coal mining since self-sufficiency rates of the E.U. are at $60 \%$ for coal, $16 \%$ for Natural Gas and only 5\% for Oil and petroleum products (in 2019) [27]. The Horizon 2020 project TRACER supports regions in Bulgaria, Germany, Greece, Czech Republic, Poland, Romania, Serbia, Ukraine and the United Kingdom in designing or re-designing their Research and Innovation strategies. The project "analyses the impact of the energy transition, in terms of social change, communities shrinking, migration, demographic ageing, poverty, high youth unemployment rates and participation to education and training" in intensive coal regions [28]. The mono-industrial character of these regions makes them specifically vulnerable to respective socioeconomic challenges and asks for dedicated measures, especially regarding re-skilling, job creation, a productive re-usage of the industrial landscape, investments in infrastructure and addressing legal issues related to land ownership. Shifting the focus from primary economic sectors to secondary or tertiary sectors might not be feasible for some of these regions; thus, coupling fossil-fuel phaseout with bioeocomy actions are promising strategies. A regional bioeconomy transition 
example is reported for the chemistry park "Schwarzheide" with leading research parties developing and pioneering in the deployment, together with the BASF company and other plastics processing companies, of bioplastics and biodegradable synthetics [29]. The strengthening of primary economic sectors in these regions will have to focus on sustainable management of agriculture and forestry for a circular bioeconomy. The circular bioeconomy sectors will cover multiple services, including electricity, heat, chemicals, bio-based materials, food/feed and services on ecosystems and the carbon budget. Respective bioeconomy concepts stand in stark contrast to a direct substitution of coal with biomass for electricity-only at the same scales of incumbent coal-fired power plants. Subsidies for bioelectricity and electricity-only are already phased out, e.g. in the Netherlands to re-orientate limited biomass resource potentials to economic sectors, which are more challenging to abate [30]. An obligatory phase-out is proposed by the European Commission for all Member States, starting with 2026, except for Bioenergy Carbon Capture and Storage (BECCS) or plants located in a "region identified in a territorial just transition plan" [31].

\subsubsection{Discussion on Multilevel governance for biomass mobilization}

The E.U. is a valuable case study for biomass mobilization strategies due to its great variety in biomes, economic structures, governmental forms and cultures but with the ambition to agree on the direction forward without inhibiting the diversity in approaches for the actual progress. It is not surprising that the individual member states themselves have a similar governance philosophy, resulting in a highly dynamic patchwork of legislative structures. The Multilevel governance (MLG) concept provides a framework for acknowledging the interactions between the different spatial or organizational resolutions while giving room for a more coherent policy mix across these resolutions and across sectors. An MLG-view is essential, especially for enabling local and regional energy and climate initiatives. [32], for example, "analyses the existing energy planning governance in Austria throughout the MLG-structure by focusing on the alignment between the local energy and climate initiatives and the national and E.U. goals." They find that a "general willingness of Austrian municipalities to take part in local energy actions" as well as "cooperation of different levels of governance from the top-down and bottom-up perspective" via local, regional and inter-regional initiatives such as the e5-Programme of energy-efficient municipalities, KEM - Klima- und Energiemodellregionen, CoM - Covenant of Mayors can be observed. Based on the identified shortcomings, especially concerning data availability and spatial energy planning for renewables crossing different jurisdictions and responsibilities, the paper recommends extending the existing governance on multiple levels with a more flexible MLG, including neighbourhoods and zones and their interconnection with varying levels up to the European Union (see Figure 2). Exemplary action points in such a framework could include "blueprint[s] for pioneering feasible regional energy initiatives". In contrast, regional sustainable development goals need to be integrated into national energy transition policy [33]. 


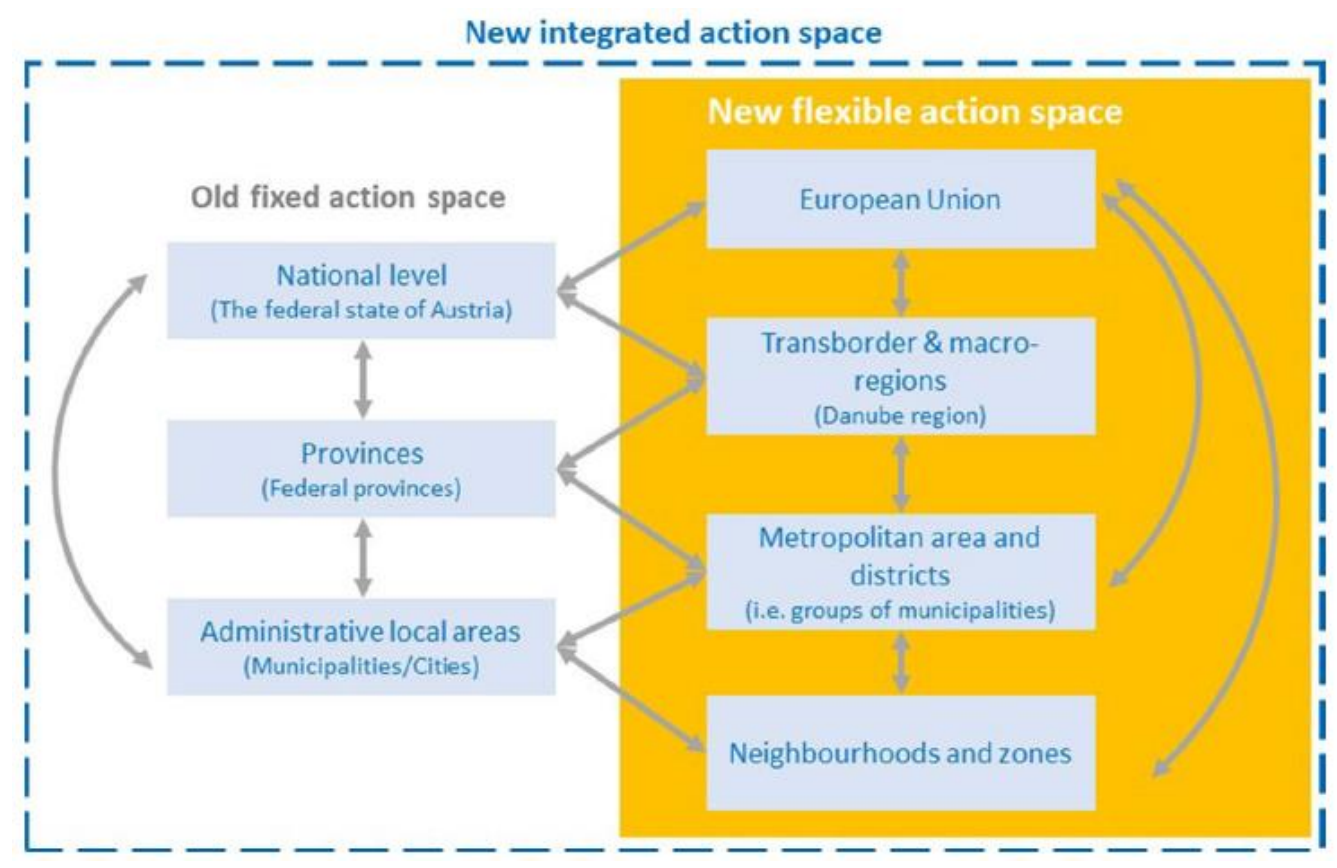

Figure 2: New integrated action space for Multilevel governance. Another sub-space underneath.

"Neighbourhoods and zones" is missing for communities of connected individuals (e.g. via an energy investment or also online) Source: [32] modified from (Jacquier C., 2010)

Renewable local energy initiatives historically focused on tackling problems related to social acceptance, such as the 'nimby'(not in my backyard)-phenomenon. Today, especially modularity of renewable electricity generation, prosumer frameworks and demand-side management are rather coined by questions on social participation instead of acceptance. Participatory processes in governance and investments and in providing energy production and consumption flexibility or engaging and nudging social networks to enhanced energy efficiency or more sustainable consumption hold significant potentials, not yet recognized, e.g., in energy system planning [34-36].

The RED acknowledges the manifold "opportunities for growth and employment that investments in the regional and local production of energy from renewable sources bring". The regional and local development opportunities include "export prospects, social cohesion and employment opportunities, particularly SMEs and independent energy producers", with decentralization fostering community development and cohesion by providing income sources and creating jobs locally. The RED and the European Economic and Social Committee (EESC) mainly address the role of civil society in the implementation of decentralized P.V.- and wind energy [37]. We would like to extend this broader socioeconomic benefits discussion to regional biomass mobilization. For example, while a civic power plant ('Bürger*innenkraftwerk') based on P.V. already boosts the possibilities for participation manifold compared to a fossilbased power plant based on energy carrier imports, a local CHP-plant connected to a district heating network and supplied by forestry residues from forests primarily cultivated for stem-wood for wood construction and engineered wood products must exhibit an even higher societal participation potential. Socioeconomic benefits of regional bioeconomies such as income, employment and net-profit for and of the engaged stakeholders are vital parameters to highlight here for policymakers and society (see, e.g. [38]). But also, the "inclusion of unique types of possibilities that each town or location offers" [39] needs to be taken into account, even though this might be more difficult to assess quantitatively. More indirect societal benefits include "protection against unpredictable energy pricing, improved energy access and security, reduction of transmission and distribution costs, independence from multinational utility interests 
and strategies and increased feasibility of renewable energy deployment within the framework of decentralized business cases" (EESC, 2014) in [33]. First, quantification and assessments of the discussed aspects will have to be modelled in energy systemand bioeconomy models. Therefore, and following [35], we urge to take "heterogeneity of actors, public acceptance and opposition, public participation and ownership" into account, to explore the social dimension and benefits of regional biomass mobilization. 


\subsection{Mobilization through technological innovation}

Biomass mobilization will most likely be enhanced through various innovation types; Organizational/institutional and social innovations can extend technological innovation. Organizational/institutional innovations address "changes in and among various organizational aspects of functions [of an organization or institution]", e.g. "the idea of networks - involving actors inside and outside [of the organization]" [40]. Social innovation is defined as "preferences of consumers, citizens, and workers for the types of products, services, environmental quality, leisure activities, and work they want" as well as respective changes in their behaviour and interactions [40]. Still, and for the last assessment level, we first and foremost focus on the market introduction and diffusion of innovations in the bioenergy supply chain technologies.

\subsubsection{Decentralized pre-treatment}

Classical, mechanical pre-treatment processes include chipping, pelletization, briquetting and bailing of biomass, which reduces transport and handling costs and better facilitates the storage and trade of densified bioenergy carriers [41]. Torrefaction, a mild form of pyrolysis, can further enhance relevant properties of the bioenergy carriers such as energy density, grindability and hydrophobicity [42]. Pyrolysis to maximize the liquid fraction of the output [43], hydrothermal treatment [44,45], upgrading of biogas from anaerobic digestion [46] or from biomass gasification to biomethane [47] are other strategies to facilitate biomass mobilization. A large number of publications focused on the impact of densification technologies on decreasing supply chain costs [48] to promote biomass commodification and trade [49] and to improve conversion efficiency for example, through gasification [50]. In contrast to properties related to trade also the value of energy and carbon being reliably stored over a long time becomes particularly relevant in a Circular Bieoconomy. This value is based on improved volumetric energy densities and suitability for storage in existing infrastructures in light of flexibility needs due to increasing shares of intermittent renewable energy production.

\subsubsection{Mobile/portable pre-treatment}

Investments in conversion- and pre-treatment plants are primarily driven by economies of (unit-) scale. It is recommended to optimize between plant size and the "respective feedstock supply distances for various feedstocks, supply modes and feedstock yield, availability and accessibility combinations" [41]. This obvious connection has farreaching consequences, including the need for pre-treatment steps based on commodity markets (see section 3.3), emerging overcapacities with increasing feedstock competition and tendencies to create vertically integrated supply chains.

Still, some niche actors aim to down-scale respective stationary technologies for them to become relocatable, transportable or even mobile. [51] outline in a detailed cost comparison how the economy of scale results in the issue that "the production of biofuels using mobile and transportable facilities is significantly more costly than production at a stationary or relocatable facility." A more recent project, 'mobileflip.eu' from VTT \& SLU, acknowledges that the added value of the smallest functional unit would be reflected by its flexibility to switch between feedstocks that are scattered spatially but also in time. [52] outline the LCA of mobile pelletization, torrefaction, slow pyrolysis, hydrothermal pre-treatment and carbonisation. Demonstration projects are furthermore described in [53,54] for mobile bio-oil production (i.e. the Renewable Oil International LCC) based on a relatively old refinery concept from [55] and another slow pyrolysis for biochar production (Schatz Energy Research Center) as an alternative to slash pile burning [56,57]. Some commercialized concepts exist such as the relocatable shipping container 'PelletBox' by Prodesa and mobile pelletization plants such as the 
'Krone Premos 5000', the 'Schaider Groups Pelletec', the 'Gmco mobile pellet plant' and the 'Proxipel concept'.

\subsubsection{GIS supported planning and harvesting}

[58] classifies energy system models regarding their (1) decision-making hierarchy (strategic, tactical, operational) and (2) the level of technology aggregation (unit operation, plant, supply chain, energy sector and whole economy). However, we can observe supply chain innovation and the utilisation of Geographic Information Systems (GIS) on all three hierarchy levels and imagine supply chain management to become the backbone of connecting organizational planning to mobilize biomass for a circular bioeconomy.

However, a notable literature review on biomass supply chain optimization [59] finds that "GIS [is] mainly used in a strategic context because they lack the short and mediumterm temporal dimension that is required for tactical and operational decisions." They are often applied to find economically optimal solutions for mobilizing forestry residues. In contrast to forestry biomass, optimization of agricultural residues and/or based on environmental or social parameters (or a combination thereof) are discussed to be less plentiful [60]. Economic optimization addresses minimizing costs for public endeavours and society, e.g., drafting policy recommendations or maximising revenues for private projects and investment decisions. The 'BeWhere model' (based on [61]) for example, "identifies the localization, size and technology of the renewable energy system that should be applied in a specific region" while Frombo et al. in [59] provide a 'GIS-based Environmental Decision Support System (EDSS)' to support investment decisions for location and size of pre-treatment plants for forest residues.

The utilization of GIS data in a strategic context includes decision variables such as facility location, -capacity/size, -technology or -type and biomass sourcing or -allocation between facilities. In contrast, tactical models aim at inventory planning and ask how much to harvest, when to harvest, inventory control and fleet management such as transport mode optimization, shipment size, routing and scheduling. These models are mainly business-oriented, such for example, the 'VITO MooV model' (based on [62]) optimizing supply chain configurations, including decisions on transport mode planning, storage capacity planning and feedstock- and product variability for mediumterm (i.e. next months to years) scheduling. [63] furthermore, describe a tool for spatial and temporal optimization of forest harvesting in a user-friendly digital map, potentially bridging the gap between tactical and operational planning.

The operational context can be discussed regarding scheduling activities in a temporal granularity below months and weeks. [64] aims to optimize the daily scheduling of trucks and mobile loaders to transport biomass from satellite storage locations to a bioenergy plant and present a case study on corn stover. [65] identify the best daily routing schedule for trucks to collect sawmill residues for energy conversion in the pulp and paper industry. Besides these rather classical travelling salesman problems, the literature on biomass supply chain GIS-modeling for operational decision support is scarce. The view citations mentioned in the central reviews on biomass supply chain modelling $[59,62,66,67]$ can mostly and arguable be better grouped in the tactical or even strategic context. We acknowledge that thorough market research would be more thankful for this type of model than the scientific literature research performed for the objective of this paper. Innovations in the field of precision agriculture, including optimizing fertilizer- and pesticide application, as well as harvest scheduling, weather forecasts of high temporal and spatial resolutions but also dynamic record-keeping based on data collection from satellites, drones and on the ground (e.g., https://geomarvel.com/), can be used for increasing the mobilization of biogenic residues. Digitally guided forest management, planning for collecting and utilizing 
damaged wood from extreme weather events or minimizing soil contamination through harvesting after natural washing (rain) and optimized deployment of mobile pretreatment could be potential applications. These big data strategies can be complemented by further digitalization and mechanization efforts, e.g. in silviculture operations and with soil mechanics fundamentals to assess terrain trafficability as, e.g., currently developed in the 'H2020 EFFORTE project'.

\subsubsection{Next-generation primary sources}

Wild cards in the bioenergy and the circular bioeconomy discussions can be seen in the introduction and market diffusion of novel biogenic carbon sources and sinks for biogenic carbon. Their particular potentials for regional mobilization strategies supporting a circular bioeconomy are challenging to discuss. Alternatively, we provide a short overview of the different research frontiers that will have to be assessed in followup projects in detail.

The production of short rotation coppice (SRC) remains relatively low (see section 3.1.1). Various projects assess the potential of crops such as Miscanthus and hemp, such as the 'BBI GRACE', or agricultural prunings and plantation removal in the 'uP_Running project'. The EU-Brazil cooperation in the 'BECOOL project' addresses different annual and perennial dedicated lignocellulosic crops, together with crop and process residues such as cereal straw, sugar cane straw, bagasse, and lignin-rich residues. The 'MAGIC' and the 'ADVANCEFUEL' projects have an even broader scope for abundant oil, lignocellulosic, carbohydrate or speciality crops. Innovation for agricultural management such as optimisation of planting density, crop establishment improvements, crop rotation intercropping, multi-purpose cropping, cropping on marginal land and precision farming, and increasing the harvesting frequency, will potentially provide additional biomass. These topics are subject, e.g. to the 'LIBBIO' project, the 'SeemLA' project and the 'FORBIO' project.

Furthermore, technological advances in agriculture and forestry can still be expected through improved fertilization, breeding, crop selection, and gene editing, and genetically modified organisms not only for yield improvements but also to provide resilience against bioms' temperature tipping points caused by global warming (see, e.g. [68]). Furthermore, micro-and macro-algae produced in photobioreactors, in open ponds or harvested from the natural environment are also promising primary feedstocks and should be addressed, e.g. in bioeconomy modelling and discussions [69]. As part of the 'blue economy', this is mainly commercially realized for food or speciality food products (e.g. Omega-3 fatty acids). The high water content renders energy or chemicals production particularly energy and cost-intensive. Furthermore, services such as nutrient recycling and recirculation or as urban solutions are still in their infants, often discussed under the umbrella of Nature-Based Solutions [70].

\subsubsection{Next-generation primary sinks}

The IEA Bioenergy project on the deployment of biocarbon capturing and sequestration published three case studies of large scale BECCS coupled with CHP in Denmark [71] for bioelectricity only in the Drax Power Station in the U.K. [72] and with the waste incineration plant of Fortum Oslo Varme in Norway [73]. In addition to the 'centralized' and large-scale BECCS, more decentralized carbon storage solutions, such as halting deforestation and degradation, have the most significant carbon emissions mitigation potential followed by afforestation (non-forest areas to forests) as outlined, e.g., in [74], reforestation (deforested areas to forests) (see [75]) and forest restoration (degrading forest to healthy forest). (IPCC, 2019) Furthermore, cited in (Fritsche et al., 2020) lists biochar addition to soil improving water holding capacity and nutrient use efficiency while sequestering carbon. Especially under the light of Climate Change, we want to 
stress that these decentralized carbon management strategies will require substantial efforts attracting skilled labour to rural areas and providing mobilization opportunities for circular bioeconomy feedstock. 


\subsection{Market creation for biomass mobilization}

Zooming into the regional context of biomass mobilization, we find that existing legislative frameworks (section 3.1) and readily deployable technologies and niche innovations (section 3.2) are often pre-conditions to establish economic activities but do not necessarily result in such. The creation and establishment of dedicated and functioning physical markets, regional-, interregional and international trade depend on additional factors, such as market competitiveness and -liquidity [76]. In the following pages, we provide and discuss selected strategies on the market creation level for the mobilization of low-value and heterogenous biomass feedstock.

\subsubsection{Market catalysts for wastes, residues, post-consumer products $\mathcal{E}$ secondary raw materials}

Regarding European efforts to transform the economy, the European Bioeconomy Strategy states that "to be successful, the European bioeconomy needs to have sustainability and circularity at its heart." [17] A comprehensive European policy overview on circularity measures can be found in [2] who outlines, that even though the E.U. can be seen as a leader in circularity, its actions mainly focus on the end-of-life phase of consumables so far, while avoiding waste through improved quality and repair options are rather novel concepts. Waste collection, processing and treatment gained a high priority in many E.U. Member States, distinguished by waste fractions e.g. containing fossil-based plastic, biogenic waste and electronic waste. The E.U. Circular Economy action plan [77], thus goes a step further by aiming to create a secondary feedstock market, primarily focused on fossilbased plastics from waste collection but also including residues from downstream industries. This creates market opportunities for commercial waste and residues plastic collectors and distributors (e.g., see https://polymerstocklist.com/). The collection and mainly energy utilization of waste wood, also coined post-consumer wood, is already better established, resulting in small but quantifiable international trade [5]. Similarly, the collection of used cooking oil and animal fats for international trade and biodiesel production gained importance in the recent decade [78]. While used cooking oil and animal fats exhibit a limited potential for business creation, post-consumer wood from traditional applications but also from increased utilization, e.g. in a potentially growing wood-based construction sector (see, e.g. [79]), as well as novel materials such as biopolymers (see e.g. [12]), will demand residues and waste collection, processing, treatment, intermediary storage and distribution to biobased industries.

\subsubsection{Physical and virtual bio-hubs}

Decentral or regional biomass processing depots, or bio-hubs, are facilities that are discussed to overcome the mismatch between the distributed occurrence of biogenic resources and large-scale centralized conversion plants such as biorefineries [80-82]. Conceptually, by including on-site pre-processing and/or densification technologies, biohubs are enabling regional market creation to allow farmers and forest owners to convert their residues into valuable by- or even co-products in the form of bioenergy or biogenic carbon carriers. Residues collection and forwarding can be either done by the farmers themselves or third parties eventually owning mobile pre-treatment equipment (see section 3.2) or machinery to make the residues accessible. Economically feasible options for residues collection are often highly case sensitive, mainly based on low energy densities and high water content and thus limit economically viable transportation ranges [41]. Different collection options exist and should be compared on a case-by-case basis.

A dedicated project for collecting the best bio-hubs practices was initiated within the IEA Bioenergy TCP. The IEA Bioenergy Biohub project collects and disseminates case studies from different world regions and theoretical considerations regarding agri- and silvicultural residues collection centres (see https://arcg.is/qLqaK). The broad definition 
of bio-hubs by [83] to valorise opportunities such as "streamlining of processing, storage and transportation, reduction in administrative costs, making a variety of biomass types available at a single location, providing an opportunity for suppliers of biomass products to continue producing in the offseason [...], as well as a place for companies to connect and trade with one another" is used for the projects' assessment. Successful examples include the Tschiggerl Agrar $\mathrm{GmbH}$, a logistics centre for processing agricultural residues to feed, animal bedding material and fuel, but also virtual bio-hubs such as the Rosewood Network for knowledge transfer in eastern European countries, discussed in the IEA Bioenergy Biohub workshops [84].

Other virtual bio-hubs have also been initiated several times throughout history. While some aim to facilitate knowledge transfer (see Table 1), others try to establish online market platforms to trade bioenergy commodities. Projects such as 'b2bbioenergy.eu' and 'promobio.eu', 'pellet-zone.com' and 'bioexchange.com' can be named within this realm. While these projects did not succeed and homepages are not maintained anymore, the 'Biomass Commodity Exchange (BCEX)' for cellulose biomass trade within the U.S., including energy crops such as willow, poplar and switchgrass, is under construction. If virtual market platforms can alter regional trade remains to be shown. For more international trading of biomass and bioenergy commodities, the wood pellets futures from 'Euronext' but also platforms to prove the origin, especially of liquid and gaseous commodities such as the 'German Nabisy' system or national and international renewable gas registries fall in the category of virtual bio-hubs. In the Baltic States, 'Baltpool' enables the trade of biomass feedstocks and even heat, with the latter being reported a relatively underdeveloped market in other parts of the E.U [85,86]. However, the comparison, implementation, development, and impact of virtual bio-hubs could be an exciting field of energy economic research without considerable publications to date.

Similarly virtual bio-hubs are, for example, discussed for Denmark based on the 'Electronic Reverse Auction (eRA)' system to source straw for straw-based thermal power stations since 2006. The applicability of eRA for the German straw market has been discussed in [87]. A buyer initiates the auctioning by requesting a certain amount and quality of straw. Various potential suppliers now can underquote (reverse auctioning) until a determined deadline. Each buyer runs its auctioning model, while the supplier can decide on amounts, contract periods (1-3 years) and prices based on blind auctioning. However, contrary to the theory, this system still needs intensive relationship management, which results in additional work for the buyer and significant competition among the sellers. Furthermore, it has to be mentioned that eRA in Denmark mainly was implemented to stabilize a market, not to establish it. For Germany and in general for new markets, feasibility studies addressing supply and demand potential, engagement of possible stake- and shareholders, and a thorough risk assessment are recommended before auctioning systems are implemented. [87]

\subsubsection{Commoditization of intermediary products:}

In the previous years, the IEA Bioenergy TCP Task40 discussed the commodification of bioenergy carriers as a necessary step for market uptake and market creation. E.g., in [76], we present the key features of commodity markets, including trade with standardized and perfectly fungible (interchangeable) units. These product-related properties are complemented with market-related properties, such as the engagement of many buyers and sellers, resulting in high market liquidity. These properties can be expressed by international trade and equilibrating forces on the last remaining product differentiator, the product price. In [88], we try to quantify the commoditization of wood pellets based on competitive spatial equilibrium modelling using modern trade theory. The wood pellets market can be seen as a role model for possibly upcoming pre-treated bioenergy carriers such as straw pellets, briquettes, pyrolysis oil, and biomethane and biogenic carbon-based (liquid) chemicals, including biodiesel, bioethanol and liquid 
organic hydrogen carriers (LOHC). Still, we find a relatively inefficient international wood pellets market in central Europe with high margins for traders. The identified low efficiency and low commoditization could result from low market transparency and an "intrinsic valuation of non-quality related properties like pellets colour and more regional biomass supply chains". In the article we argue, that internationally harmonized data and sustainability standardization (and awareness thereof) could steer the market towards a joint price benchmark and more stable and on average lower prices. However, we acknowledge, that this development holds the risk to drive smaller and less economic viable producers with regional supply chains out of the market.

A more critical view and direct reaction on this topic are presented in [33]; Here, commoditization is deemed "counter to generating viable regional energy projects as it reduces the stakeholder role of local agricultural biomass producers". Commoditization is addressed as a challenge with the potential impact to "seriously decelerate or weaken the movement towards energy democracy and decentralized renewable energy".

Provided supporting arguments include that longer and international supply chains give citizens "little-to-no influence over the sustainability of their energy supply" and pose a risk of distorting ecological equilibrium since they undermine efforts for (local) circularity. This critique understands the heterogeneity of regional biomass supply chains as an essential driver for the participation of diverse stakeholders, providing ownership, local revenue and job creation, and independence from multinational utility interests.

Some of these commoditization-critical arguments are not sufficiently substantiated; E.g., sustainability certification provides control over the energy supply chain, even for internationally purchased wood pellets, wood pellet supply chains, especially for residential heating, are by no means centralized. However, the overall controversy and potential trade-off between commoditization and specialization, hence between larger and efficient markets and smaller and less efficient markets, is highly relevant, especially in the light of regional and civic energy initiatives. As discussed under the legislative strategies (see section 3.1), circular bioeconomic structures have exceptionally high decentralization- and societal participation potentials. We propose that this key performance indicator (KPI) could be better measured by the number of stake- and shareholders part of a specific bioeconomy supply chain rather than by the transport distance of bioenergy or biogenic carbon carriers. Still, the number of stake- and shareholders, similar to the transport distance, contributes negatively (higher costs) to the accumulated costs of the final product/service and for the consumer. Without "giving credits" to this KPI, commoditization and the resulting (international) market efficiency indeed result in (1) less stake-/shareholder diverse supply chains and (2) relocation of supply chains to regions of lower production costs.

Sustainability certification can already ensure that efficient markets do not result in a race to the lowest environmental standards and even elevate standards and transfer higher standards to some regional markets. Additional socioeconomic certification for smaller producers, as implemented for some products (fair-trade of coffee \& tea, chocolate), can be understood as specialization of the supply chain, a critical mass of equitable supply chains however could set new standards for commodity markets. Extending sustainability certification of internationally traded biomass commodities with socioeconomic KPIs such as stake-/shareholder variety could be a promising strategy for just and regional biomass mobilization. Research on comprehensive frameworks for sustainable assessments of biobased products is performed, e.g., in the Horizon2020 STAR-ProBio project.

\subsubsection{Informative networks for knowledge exchange and market creation}


Transparency is critical for functioning international markets and is also expected to play an essential role in regional markets to support values (e.g. sustainability, stake/shareholder diversity) but also stability through the exchange of harmonized price information, spatially and temporally explicit production and consumption data and data on flows and stocks, including storage volumes. Bioenergy storage, and its flexibility service character, is of particular importance when energy systems develop towards higher implementation of intermittent renewable energies such as photo-voltaic and wind power. Market transparency induces fair competition, which can be beneficial not only for the end-users but also for the shareholders of the supply chain if the information on innovation is transparently traded and best practices are shared. Currently, market information networks are collecting, preparing and providing respective know-how and knowledge, often in cooperation with experts from industry and academia:

The IEA Bioenergy TCP and related TCPs (see Figure 3) is part of the intergovernmental OECD/IEA network. It is committed to providing scientific backed information on the level of markets, developed- and immature technologies and how their status today, opportunities and barriers for market diffusion in the upcoming decades.

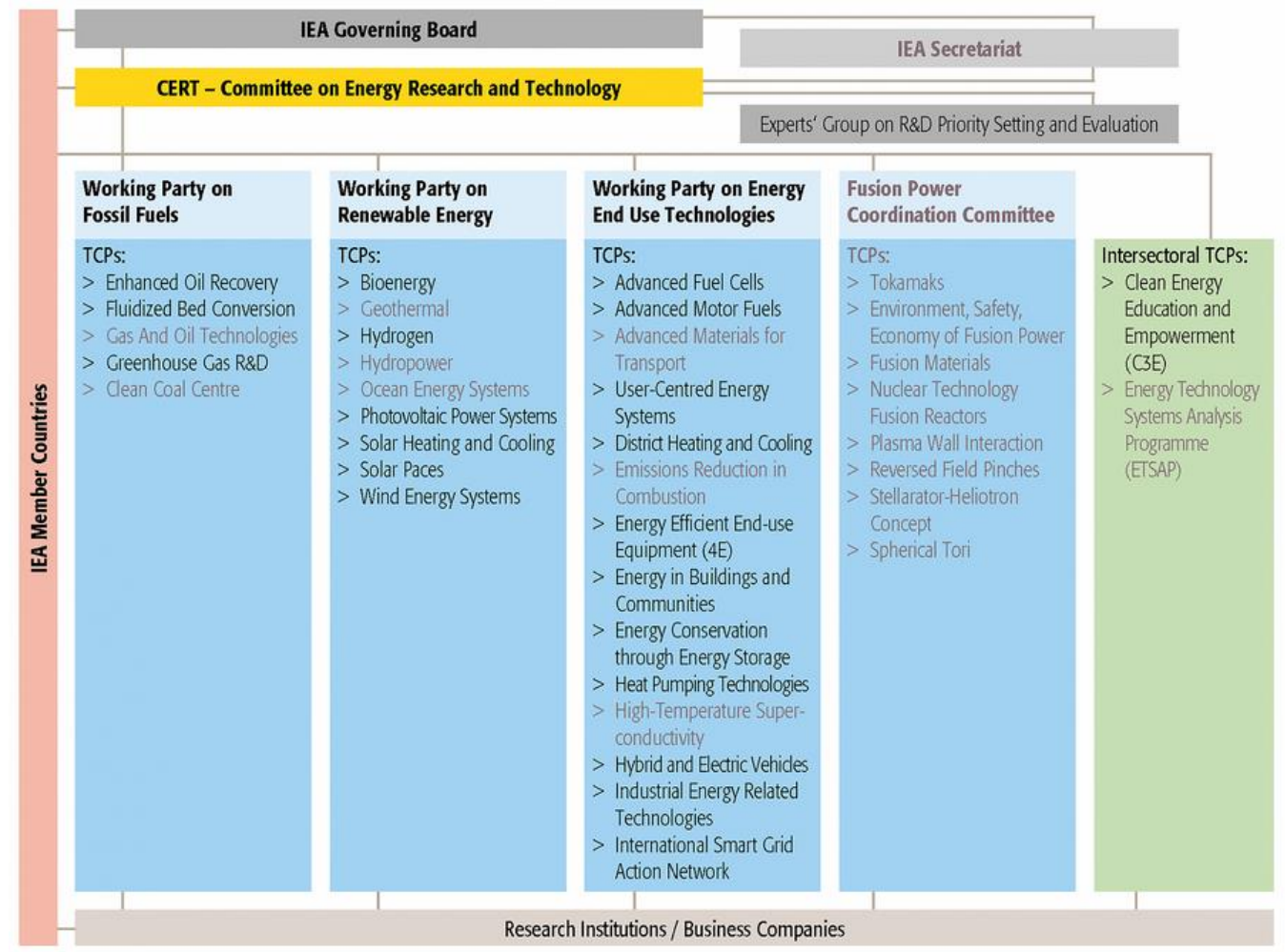

Figure 3: Structure of the IEA network and Technology Collaboration Programmes. Source: Projektfabrik

Other energy-related international and partly intergovernmental information networks include the International Renewable Energy Agency (IRENA), the U.N. initiative Sustainable Energy for All (SE4ALL), the REN21 and many more (e.g. International Energy Forum /IEF, Global Bioenergy Partnership/GBEP, BioFuture Platform, EurObserv'ER, EREC, World Energy Council). On a European level, especially the European Energy Research Alliance (EERA) has to be mentioned. While these networks focus on the exchange between countries, also considerable efforts are undertaken for inter-regional exchange of know-how and knowledge. Networks on an inter-regional and regional level often include national and regional governments and regional energy agencies, and interest groups. They are supported by international or national structural and regional development funds (see 
section 3.1). Analysing the unique selling propositions and the effectiveness of the different networks and initiatives is beyond the scope of this project. Still, it could be an exciting research topic for participatory research and research on international consortia, potentially resulting in harmonised performance metrics and ultimately improved impact on regional sustainable energy implementation. 


\section{Summary and conclusions}

In the present paper, we assess mobilization strategies for low-value and heterogenous biomass feedstock as possible input to the circular bioeconomy of tomorrow. Therefore, expertise from the IEA Bioenergy Task 40 project on international supply chains of bioenergy commodities is deployed to reflect on mobilization measures for non-commodity biogenic residues that also support regional development.

Numerous European and regional biomass and regional development action plans and dedicated policy-, funding landscapes, research-, development- and implementation projects have been deployed to support the uptake of biogenic residues. The focus of these measures shifted in the last decade from providing feedstocks for bioenergy to meet renewable energy targets to creating added value and opportunities for structurally weak and vulnerable regions. We argue that a sustainable integration of energy-, material-, nutrient- and ecosystem services holds significant decentralization and societal participation potentials, which are not yet recognized by the European Economic and Social Committee and are not accounted for in the incumbent energy system-, bioeconomy-, or economic metabolism models.

Readily deployable niche innovations throughout the entire supply chain exist and can already today support regional biomass mobilization of agriculture and forestry residues. Strategic, tactical and operational planning of management, harvesting, and processing benefits from developments in big-data and Geographic Information Systems. Processing, pre-treatment and densification technologies are readily deployable and could be scaled down for mobile or portable operation. Final carbon sinks are likely to gain in importance, decentralised carbon management practices will require substantial efforts attracting skilled labour to rural areas and providing mobilization opportunities for circular bioeconomy feedstock.

However, market creation is often discussed as a bottleneck despite readily deployable niche innovations and legislative frameworks. We address the concept of regional biomass processing depots and stress their value not only for collection and distribution of diverse feedstocks to multiple economic sectors but also for storage and the respective flexibility services in an energy system of high intermittent renewables production shares. Besides these physical bio-hubs also virtual bio-hubs exist in the form of trading platforms, however with low success rates. Finally, we highlight the potential role of socioeconomic certification complementing sustainability certification to account for the stakeand shareholder variety of biomass supply chains. This could reduce the risk for competitive and international markets degrading environmental and socioeconomic standards.

Due to the broad scope of the presented study, we have to acknowledge multiple limitations, partly addressed as future research in the results and discussion section. We shortly explain the concept of Multi-Level Governance. By trans-disciplinary research, Multi-Level Governance implementation holds promising opportunities for regional development and biomass for bioeconomy mobilization. Physical and virtual bio-hubs, mobile pre-treatment and Geographic Information supported mobilization, knowledge-exchange platforms and information networks such as the International Energy Agency Bioenergy Technology Collaboraiton Plattform require scientific support in parameterizing and evaluating their performances. The quantification of the systemic value of strengthening knowledge-based primary economic sectors would be another exciting research field addressing meaningful jobs and activities supporting structurally vulnerable regions. Therefore, economic metabolism modelling should account for multiple assessment criteria and modelling functions, based on all types of resources, including monetary, natural, human, CO2-budget and time. 


\begin{abstract}
Author Contributions: Conceptualization, F.S. and A.P.; methodology, F.S. and A.P.; investigation, F.S. and A.P.; writing-original draft preparation, F.S.; writing - review and editing, F.S. and R.H.; project administration, F.S.; funding acquisition, F.S. and R.H.; All authors have read and agreed to the published version of the manuscript.

Funding: This research was funded by the IEA Bioenergy TCP Task40 and the BMK, FFG grant number 876720

Conflicts of Interest: The authors declare no conflict of interest. The funders had no role in the design of the study; in the collection, analyses, or interpretation of data; in the writing of the manuscript, or in the decision to publish the results.
\end{abstract}

\title{
References
}

[1] EC. COMMUNICATION FROM THE COMMISSION TO THE EUROPEAN PARLIAMENT, THE COUNCIL, THE EUROPEAN ECONOMIC AND SOCIAL COMMITTEE AND THE COMMITTEE OF THE REGIONS A sustainable Bioeconomy for Europe: Strengthening the connection between economy, society and the environment. 2018.

[2] Milios L. Advancing to a Circular Economy: three essential ingredients for a comprehensive policy mix. Sustain Sci 2018;13:861-78. https://doi.org/10.1007/s11625-017-0502-9.

[3] EC. A European Strategy for Plastics in a Circular Economy. 2018.

[4] BBI JU. Draft proposal for aEuropean Partnership under Horizon Europe European Partnership for a Circular biobased Europe: sustainable innovation for new local value from bio-waste and biomass (CBE). 2020.

[5] Junginger HM, Mai-Moulin T, Daioglou V, Fritsche U, Guisson R, Hennig C, et al. The future of biomass and bioenergy deployment and trade: a synthesis of 15 years IEA Bioenergy Task 40 on sustainable bioenergy trade. Biofuels, Bioproducts and Biorefining 2019;13:247-66. https://doi.org/10.1002/bbb.1993.

[6] Camia A, Robert N, Jonsson R, Pilli R, Garcia-Condado S, Lopez-Lozano R, et al. Biomass production, supply, uses and flows in the European Union, 2018. Integrated Assessment 2018:126.

[7] Mandley SJ, Daioglou V, Junginger HM, van Vuuren DP, Wicke B. EU bioenergy development to 2050. Renewable and Sustainable Energy Reviews 2020;127:109858. https://doi.org/10.1016/j.rser.2020.109858.

[8] Brosowski A, Krause T, Mantau U, Mahro B, Noke A, Richter F, et al. How to measure the impact of biogenic residues, wastes and by-products: Development of a national resource monitoring based on the example of Germany. Biomass and Bioenergy 2019;127. https://doi.org/10.1016/j.biombioe.2019.105275.

[9] Haase M, Rösch C, Ketzer D. GIS-based assessment of sustainable crop residue potentials in European regions. Biomass and Bioenergy 2016;86:156-71. https://doi.org/10.1016/j.biombioe.2016.01.020.

[10] Hamelin L, Borzęcka M, Kozak M, Pudełko R. A spatial approach to bioeconomy: Quantifying the residual biomass potential in the EU-27. Renewable and Sustainable Energy Reviews 2019;100:127-42. https://doi.org/10.1016/j.rser.2018.10.017.

[11] Searle S, Malins C. A reassessment of global bioenergy potential in 2050. GCB Bioenergy 2015;7:328-36. https://doi.org/10.1111/gcbb.12141.

[12] Schipfer F, Kranzl L, Leclère D, Sylvain L, Forsell N, Valin H. Advanced biomaterials scenarios for the EU28 up to 2050 and their respective biomass demand. Biomass and Bioenergy 2017;96:19-27. https://doi.org/10.1016/j.biombioe.2016.11.002.

[13] Chang M, Thellufsen JZ, Zakeri B, Pickering B, Pfenninger S, Lund H, et al. Trends in tools and approaches for modelling the energy transition. Applied Energy 2021;290:116731. https://doi.org/10.1016/j.apenergy.2021.116731.

[14] EC. The European Green Deal. 2019.

[15] EC. Stepping up Europe's 2030 climate ambition. Investing in a climate-neutral future for the benefit of our people. 2020. 
[16] EC. DIRECTIVE OF THE EUROPEAN PARLIAMENT AND OF THE COUNCIL amending Directive (EU) 2018/2001 of the European Parliament and of the Council, Regulation (EU) 2018/1999 of the European Parliament and of the Council and Directive 98/70/EC of the European Parliament and of the Council as regards the promotion of energy from renewable sources, and repealing Council Directive (EU) 2015/652. 2021.

[17] EC. COMMISSION STAFF WORKING DOCUMENTAccompanying the documentCOMMUNICATION FROM THE COMMISSION TO THE EUROPEAN PARLIAMENT, THE COUNCIL, THE EUROPEAN ECONOMIC AND SOCIAL COMMITTEE AND THE COMMITTEE OF THE REGIONS A sustainable Bioeconomy for Europe: Strengthening the connection between economy, society and the environment. 2018.

[18] EC. A long-term Vision for the EU's Rural Areas - Towards stronger, connected, resilient and prosperous rural areas by 2040. 2021.

[19] EC. A Farm to Fork Strategy for a fair, healthy and environmentally-friendly food system. 2020.

[20] EC. New EU Forest Strategy for 2030. 2021.

[21] EC. EU Biodiversity Strategy for 2030. 2020.

[22] Emmerling C, Pude R. Introducing Miscanthus to the greening measures of the EU Common Agricultural Policy. GCB Bioenergy 2017;9:274-9. https://doi.org/10.1111/gcbb.12409.

[23] Parra-López C, Holley M, Lindegaard K, Sayadi S, Esteban-López G, Durán-Zuazo VH, et al. Strengthening the development of the short-rotation plantations bioenergy sector: Policy insights from six European countries. Renewable Energy 2017;114:781-93. https://doi.org/10.1016/j.renene.2017.07.098.

[24] EC. Communication From The Commission. Biomass action plan COM(2005) 628. 2005.

[25] Kautto N, Peck P. Regional biomass planning - Helping to realise national renewable energy goals? Renewable Energy 2012;46:23-30. https://doi.org/10.1016/j.renene.2012.03.024.

[26] Elbersen B, de Groot H, Staritsky I, Dees M, Datta P, Leduc S. A full technical description of the integrated toolset, central database and general user interface developed in WP4. S2Biom Project Grant Agreement nº68622. 2017.

[27] Eurostat. Energy from renewable sources - shares 2021. https://ec.europa.eu/eurostat/web/energy/data/shares (accessed October 4, 2021).

[28] Radulov L, Nikolaev A, Genadieva V, Frouz J. Report on social challenges and re-skilling needs of the workforce solutions in the TRACER target regions. TRACER D3.4. 2020.

[29] Knoche D, Mergner R, Janssen R, Doczekal C. Fact Sheet:Chemistry park "Schwarzheide"Conversion of a lignitebasedrefineryinto a showcase for industrial transition. TRACER Fact Sheet. 2019.

[30] Sociaal-Economische Raad. Biomass in the balance 2020:30.

[31] EC. Proposal for a Directive of the European Parliament and of the Council amending Directive (EU) $2018 / 2001$. COM(2021) 557 final. 2021.

[32] Dobravec V, Matak N, Sakulin C, Krajačić G. Multilevel governance energy planning and policy: a view on local energy initiatives. Energy, Sustainability and Society 2021;11:2. https://doi.org/10.1186/s13705-020-00277-y.

[33] McGovern G, Klenke T. Towards a driver framework for regional bioenergy pathways. Journal of Cleaner Production 2018;185:610-8. https://doi.org/10.1016/j.jclepro.2018.02.251.

[34] Aryanpur V, O'Gallachoir B, Dai H, Chen W, Glynn J. A review of spatial resolution and regionalisation in national-scale energy systems optimisation models. Energy Strategy Reviews 2021;37:100702. https://doi.org/10.1016/j.esr.2021.100702.

[35] Krumm A, Süsser D, Blechinger P. Modelling social aspects of the energy transition: What is the current representation of social factors in energy models? Energy 2022;239:121706. https://doi.org/10.1016/j.energy.2021.121706. 
[36] Süsser D, Gaschnig H, Ceglarz A, Stavrakas V, Flamos A, Lilliestam J. Better suited or just more complex? On the fit between user needs and modeller-driven improvements of energy system models. Energy 2022;239:121909. https://doi.org/10.1016/j.energy.2021.121909.

[37] EESC. EU Renewable Energy Directive. The role of civil society in the implementation of the EU Renewable Energy Directive: An impact study across six Member States. 2014.

[38] Wang X, Li K, Song J, Duan H, Wang S. Integrated assessment of straw utilization for energy production from views of regional energy, environmental and socioeconomic benefits. Journal of Cleaner Production 2018;190:78798. https://doi.org/10.1016/j.jclepro.2018.04.191.

[39] Lehtonen O, Okkonen L. Socio-economic impacts of a local bioenergy-based development strategy - The case of Pielinen Karelia, Finland. Renewable Energy 2016;85:610-9. https://doi.org/10.1016/j.renene.2015.07.006.

[40] Ashford NA. Technological, Organisational, and Social Innovation as Pathways to Sustainability. Innovation The Pathway to Threefold Sustainability 2001.

[41] Schipfer F, Kranzl L. Techno-economic evaluation of biomass-to-end-use chains based on densified bioenergy carriers (dBECs). Applied Energy 2019;239:715-24. https://doi.org/10.1016/j.apenergy.2019.01.219.

[42] Thrän D, Witt J, Schaubach K, Kiel J, Carbo M, Maier J, et al. Moving torrefaction towards market introduction Technical improvements and economic-environmental assessment along the overall torrefaction supply chain through the SECTOR project. Biomass and Bioenergy 2016. https://doi.org/10.1016/j.biombioe.2016.03.004.

[43] Bridgwater AV. Review of fast pyrolysis of biomass and product upgrading. Biomass and Bioenergy 2012;38:6894. https://doi.org/10.1016/j.biombioe.2011.01.048.

[44] Gollakota ARK, Kishore N, Gu S. A review on hydrothermal liquefaction of biomass. Renewable and Sustainable Energy Reviews 2018;81:1378-92. https://doi.org/10.1016/j.rser.2017.05.178.

[45] Shen Y. A review on hydrothermal carbonization of biomass and plastic wastes to energy products. Biomass and Bioenergy 2020;134:105479. https://doi.org/10.1016/j.biombioe.2020.105479.

[46] Kapoor R, Ghosh P, Kumar M, Vijay VK. Evaluation of biogas upgrading technologies and future perspectives: a review. Environ Sci Pollut Res 2019;26:11631-61. https://doi.org/10.1007/s11356-019-04767-1.

[47] Schildhauer TJ, Biollaz SMA. Fluidised bed methanation for SNG production - process development at the PaulScherrer Institut, in Synthetic Natural Gas from Coal, Dry Biomass, and Power-to-Gas Applications, T.J. Schildhauer, S.M.A. Biollaz (Eds.), Wiley \& Sons, New York, 221-229. 2016.

[48] Uslu A, Faaij APC, Bergman PCA. Pre-treatment technologies, and their effect on international bioenergy supply chain logistics. Techno-economic evaluation of torrefaction, fast pyrolysis and pelletisation. Energy 2008;33:120623. https://doi.org/10.1016/j.energy.2008.03.007.

[49] Lamers P, Junginger M, Hamelinck C, Faaij A. Developments in international solid biofuel trade - An analysis of volumes, policies, and market factors. Renewable and Sustainable Energy Reviews 2012;16:3176-99. https://doi.org/10.1016/j.rser.2012.02.027.

[50] Chen W-H, Peng J, Bi XT. A state-of-the-art review of biomass torrefaction, densification and applications. Renewable and Sustainable Energy Reviews 2015;44:847-66. https://doi.org/10.1016/j.rser.2014.12.039.

[51] Polagye BL, Hodgson KT, Malte PC. An economic analysis of bio-energy options using thinnings from overstocked forests. Biomass and Bioenergy 2007;31:105-25. https://doi.org/10.1016/j.biombioe.2006.02.005.

[52] de la Fuente T, Bergström D, González-García S, Larsson SH. Life cycle assessment of decentralized mobile production systems for pelletizing logging residues under Nordic conditions. Journal of Cleaner Production 2018;201:830-41. https://doi.org/10.1016/j.jclepro.2018.08.030.

[53] Mirkouei A, Haapala KR, Sessions J, Murthy GS. A review and future directions in techno-economic modeling and optimization of upstream forest biomass to bio-oil supply chains. Renewable and Sustainable Energy Reviews 2017;67:15-35. https://doi.org/10.1016/j.rser.2016.08.053. 
[54] Mirkouei A, Mirzaie P, Haapala KR, Sessions J, Murthy GS. Reducing the cost and environmental impact of integrated fixed and mobile bio-oil refinery supply chains. Journal of Cleaner Production 2016;113:495-507. https://doi.org/10.1016/j.jclepro.2015.11.023.

[55] Badger PC, Fransham P. Use of mobile fast pyrolysis plants to densify biomass and reduce biomass handling costs -A preliminary assessment. Biomass and Bioenergy 2006;30:321-5. https://doi.org/10.1016/j.biombioe.2005.07.011.

[56] Puettmann M, Sahoo K, Wilson K, Oneil E. Life cycle assessment of biochar produced from forest residues using portable systems. Journal of Cleaner Production 2020;250:119564. https://doi.org/10.1016/j.jclepro.2019.119564.

[57] Sahoo K, Bilek E, Bergman R, Mani S. Techno-economic analysis of producing solid biofuels and biochar from forest residues using portable systems. Applied Energy 2019;235:578-90. https://doi.org/10.1016/j.apenergy.2018.10.076.

[58] Subramanian ASR, Gundersen T, Adams TA. Modeling and Simulation of Energy Systems: A Review. Processes 2018;6:238. https://doi.org/10.3390/pr6120238.

[59] Ba BH, Prins C, Prodhon C. Models for optimization and performance evaluation of biomass supply chains: An Operations Research perspective. Renewable Energy 2016;87:977-89. https://doi.org/10.1016/j.renene.2015.07.045.

[60] Cambero C, Sowlati T. Assessment and optimization of forest biomass supply chains from economic, social and environmental perspectives - A review of literature. Renewable and Sustainable Energy Reviews 2014;36:62-73. https://doi.org/10.1016/j.rser.2014.04.041.

[61] Leduc S. Development of an optimization model for the location of biofuel production plants. Lulea: Luleå tekniska universitet; 2009.

[62] De Meyer A, Cattrysse D, Van Orshoven J. Considering biomass growth and regeneration in the optimisation of biomass supply chains. Renewable Energy 2016;87:990-1002. https://doi.org/10.1016/j.renene.2015.07.043.

[63] Vopěnka P, Kašpar J, Marušák R. GIS tool for optimization of forest harvest-scheduling. Computers and Electronics in Agriculture 2015;113:254-9. https://doi.org/10.1016/j.compag.2015.03.001.

[64] An H. Optimal daily scheduling of mobile machines to transport cellulosic biomass from satellite storage locations to a bioenergy plant. Applied Energy 2019;236:231-43. https://doi.org/10.1016/j.apenergy.2018.11.073.

[65] Zamar DS, Gopaluni B, Sokhansanj S. Optimization of sawmill residues collection for bioenergy production. Applied Energy 2017;202:487-95. https://doi.org/10.1016/j.apenergy.2017.05.156.

[66] Atashbar NZ, Labadie N, Prins C. Modeling and optimization of biomass supply chains: A review and a critical look. IFAC-PapersOnLine 2016;49:604-15. https://doi.org/10.1016/j.ifacol.2016.07.742.

[67] Mafakheri F, Nasiri F. Modeling of biomass-to-energy supply chain operations: Applications, challenges and research directions. Energy Policy 2014;67:116-26. https://doi.org/10.1016/j.enpol.2013.11.071.

[68] Duffy KA, Schwalm CR, Arcus VL, Koch GW, Liang LL, Schipper LA. How close are we to the temperature tipping point of the terrestrial biosphere? Science Advances 2021;7:eaay1052. https://doi.org/10.1126/sciadv.aay1052.

[69] Welfle A, Thornley P, Röder M. A review of the role of bioenergy modelling in renewable energy research \& policy development. Biomass and Bioenergy 2020;136:105542. https://doi.org/10.1016/j.biombioe.2020.105542.

[70] Gómez Martín E, Giordano R, Pagano A, van der Keur P, Máñez Costa M. Using a system thinking approach to assess the contribution of nature based solutions to sustainable development goals. Science of The Total Environment 2020;738:139693. https://doi.org/10.1016/j.scitotenv.2020.139693.

[71] Bang C. Deployment of bio-CCS: case studyon bio-combined heat and powerHOFOR Amager CHP, Copenhagen, Denmark. 2021.

[72] Marris ZM. Deployment of bio-CCS: case study on bioelectricityDraxPower Station, United Kingdom. 2021.

[73] Becidan M. Deployment of bio-CCS:case study onWaste-to-EnergyFortum Oslo Varme (FOV), Oslo, Norway. 2021. 
[74] Houghton RA, Nassikas AA. Negative emissions from stopping deforestation and forest degradation, globally. Global Change Biology 2018;24:350-9. https://doi.org/10.1111/gcb.13876.

[75] Chazdon RL, Broadbent EN, Rozendaal DMA, Bongers F, Zambrano AMA, Aide TM, et al. Carbon sequestration potential of second-growth forest regeneration in the Latin American tropics. Science Advances 2016;2:e1501639. https://doi.org/10.1126/sciadv.1501639.

[76] Olsson O, Lamers P, Schipfer F, Wild M. Chapter 7 - Commoditization of Biomass Markets. Developing the Global Bioeconomy, Academic Press; 2016, p. 139-63.

[77] EC. A new Circular Economy Action Plan For a cleaner and more competitive Europe. 2020.

[78] Pelkmans L, Goh CS, Junginger M, Parhar R, Bianco E, Pellini A, et al. Impact of promotion mechanisms for advanced and low-iLUC biofuels on markets. Summary Report. IEA Bioenergy Task 40; 2014.

[79] Churkina G, Organschi A, Reyer CPO, Ruff A, Vinke K, Liu Z, et al. Buildings as a global carbon sink. Nature Sustainability 2020;3:269-76. https://doi.org/10.1038/s41893-019-0462-4.

[80] Lamers P, Roni MS, Tumuluru JS, Jacobson JJ, Cafferty KG, Hansen JK, et al. Techno-economic analysis of decentralized biomass processing depots. Bioresource Technology 2015;194:205-13. https://doi.org/10.1016/j.biortech.2015.07.009.

[81] Maheshwari P, Singla S, Shastri Y. Resiliency optimization of biomass to biofuel supply chain incorporating regional biomass pre-processing depots. Biomass and Bioenergy 2017;97:116-31. https://doi.org/10.1016/j.biombioe.2016.12.015.

[82] Soren A, Shastri Y. Optimization based design of a resilient biomass to energy system. In: Friedl A, Klemeš JJ, Radl S, Varbanov PS, Wallek T, editors. Computer Aided Chemical Engineering, vol. 43, Elsevier; 2018, p. 797-802. https://doi.org/10.1016/B978-0-444-64235-6.50140-6.

[83] Nasso S, Sweazey B, Gagnon B. Bio-hubs as Keys to Successful Biomass Supply for the Bioeconomy. Report from Joint IEA Bioenergy Task 43 \& Natural Resources Canada Workshopheld in Ottawa on 6 March 2020. IEA Bioenergy: Task 43. 2020.

[84] Kulišić B, Brown M, Dimitriou I, Murphy EK, Gagnon B. Bio-hubs as keys to successful biomass supply integration for bioenergy within the bioeconomy 2020:35.

[85] Liu W, Klip D, Zappa W, Jelles S, Kramer GJ, van den Broek M. The marginal-cost pricing for a competitive wholesale district heating market: A case study in the Netherlands. Energy 2019;189:116367. https://doi.org/10.1016/j.energy.2019.116367.

[86] Wang J, You S, Zong Y, Cai H, Træholt C, Dong ZY. Investigation of real-time flexibility of combined heat and power plants in district heating applications. Applied Energy 2019;237:196-209. https://doi.org/10.1016/j.apenergy.2019.01.017.

[87] Pfeiffer A, Mertens A, Brosowski A, Thrän D. Der Strohmarkt in Deutschland. 2019.

[88] Schipfer F, Kranzl L, Olsson O, Lamers P. The European wood pellets for heating market - Price developments, trade and market efficiency. Energy 2020;212:118636. https://doi.org/10.1016/j.energy.2020.118636.

[89] Eggler L, Indinger A, Zwieb L. Mapping of activities in Technology Collaboraiton Programmes (TCPs) in the Energy Technology Network of the International Energy Agency (IEA) 2018:64. 